Journal of Animal and Veterinary Advances $10(4)$ : 437-442, 2011

ISSN: $1680-5593$

(C) Medwell Journals, 2011

\title{
Preliminary Phytochemical Screening and in vitro Anthelmintic Effects of Aqueous Extracts of Salvadora persica and Terminalia avicennoides Against Strongyline Nematodes of Small Ruminants in Nigeria
}

\author{
${ }^{1}$ Datsu Kalip Reuben, ${ }^{2,3}$ Slyranda Baltini Aji, ${ }^{5}$ Wycliff Andrew and ${ }^{4}$ Fanna Inna Abdulrahaman \\ ${ }^{1}$ Department of Basic Sciences, ${ }^{2}$ Department of Animal Health and Production Technology, \\ Adamawa State College of Agriculture, P.M.B. 2088, Ganye, Nigeria \\ ${ }^{3}$ Department of Veterinary Physiology, Pharmacology and Biochemistry, \\ ${ }^{4}$ Department of Chemistry, University of Maiduguri, P.M.B. 1069, Maiduguri, Nigeria \\ ${ }^{5}$ National Agency for Food and Drug Administration and Control, \\ Port Inspection Directorate, Yaba-Lagos, Nigeria
}

\begin{abstract}
The traditional use of aqueous extracts of shoots and leaves of Salvadora persica L. and root bark of Terminalia avicenoides as anthelmintics in Northeastern Nigeria necessitated the need to examine these plants. This study was carried out to determine the phytochemical constituents of these extracts and determine and compared their anthelmintic efficacies against those of commercially available anthelmintics (albendazole and levamisole). The preliminary phytochemical screening of the extracts revealed the presence of tannins, flavonoids, saponins, sterols and terpens and reducing sugars in all the extracts. Antracenocides were present only in extracts of $S$. persica L. shoots and the root bark of T. avicennoides. Similarly, flavone aglycones were detected only in extracts of $S$. persica $\mathrm{L}$. leaves and the root bark of $T$. avicennoides. Basic alkaloids were detected in extracts of $T$. avicennoides stem bark and $S$. persica shoots. The anthelmintic study showed that all the extracts exhibit in vitro anthelmintic activities against strongyline nematodes in a concentration dependent fashion and such effects were significant $(\mathrm{p}<0.001)$ when compared to those of albendazole and levamisole at the concentrations used in the experiment. The result of the study indicated that the extracts contained phytochemicals that are known to possess various pharmacologic activities and of therapeutic benefits, one or a combination of which could be responsible for the in vitro anthelmintic effects observed. The study also validated the basis for the traditional use of these plants as anthelmintics in North Eastern Nigeria.
\end{abstract}

Key words: Phytochemicals, Salvadora persica, Terminalia avicennoides, anthelmintic, small ruminants, nematodes

\section{INTRODUCTION}

Helminthosis is the most common economically important infectious disease of grazing livestock especially small ruminants in the tropics and subtropics (Githiori et al., 2003a). The disease is characterized by high morbidity (Suleiman et al., 2005) and causes wastage and serious economic loss in small ruminant production thereby constituting a major constraint in the development of these species (Nawathe et al., 1985; Payne, 1990). It is also the major cause of mortality and sub-optimal productivity in these species especially under the traditional husbandry system (Fakae, 1990; Kusiluka and Kambarage, 1996). Losses in production due to helminthosis is either direct due to mortalities or indirect as a result of reduction in live-weight gains, decreased quality of skin, wool or mohair and diminished immune status of infested animals leading to increased susceptibility to other infections (Kusiluka and Kambarage, 1996). Reduced growth rate (McLeod, 1995) and decrease milk yield (Mulugeta et al., 1987) are also common findings associated with the disease.

Control of helminthosis is usually aimed at reducing its prevalence and limiting infection in order to minimize the challenge to an economically justifiable level. This is usually achieved through judicious use of anthelmintics, good management, breeding resistant stock and immunization (Kusiluka and Kambarage, 1996). However, the use of anthelmintics which is foremost among the control measures faces serious setback as a result of the emergence and spread of drug-resistant gastrointestinal parasites (Prichard, 1994; Mwamachi et al., 1995; Waller,

Corresponding Author: Slyranda Baltini Aji, Department of Animal Health and Production Technology, Adamawa State College of Agriculture, P.M.B. 2088, Ganye, Nigeria 
1997). This has been blamed on the misuse of anthelmintic drugs and probable adaptation of parasites to commercially available formulations (Mascie-Taylor and Karim, 2003) and the widespread intensive use of low quality anthelmintics (Monteiro et al., 1998). Furthermore, commercially available anthelmintics are relatively expensive (Hammond et al., 1997) and smallholder farmers are unlikely to spend their meager income to purchase these drugs for regular treatments (Kusiluka and Kambarage, 1996). This necessitates the search for alternative chemotherapeutic agents that are relatively inexpensive, readily available and to which parasites are unlikely to develop resistance (Coles and Roush, 1992; Hammond et al., 1997).

Materials from plants have been used in many parts of the world as traditional remedies against helminths that affect humans and animals and quite a number of them have been scientifically validated for their anthelmintic properties (Githiori et al., 2003a, b; Adedapo et al., 2005; Dawo and Tibbo, 2005; Suleiman et al., 2005; Max et al., 2007; Jan et al., 2008).

In northeastern part of Nigeria, the aqueous extracts of the leaves and shoots of Salvadora persica L., a member of the Salvadoraceae family and the root bark of Taminalia avicennoides of the family Combrataceae are used in traditional medicine for the treatment of a myriad of diseases including helminthes infections. Therefore, given the wide application of these plants in the traditional treatment of various conditions and as anthelmintics, there is the need to determine the chemical constituents and validate the claim for their activities.

The aim of this study was to determine the preliminary phytochemical constituents of the aqueous extracts of the shoots and leaves of Salvadora persica L. and root bark of Taminalia avicennoides and to determine and compared their anthelmintic efficacies against those of commercially available anthelmintics (albendazole and levamisole).

\section{MATERIALS AND METHODS}

Study area: The study was carried out in Borno state in the Northeastern Nigeria, located within latitude $10^{\circ} \mathrm{N}$ and $14^{\circ} \mathrm{N}$ and longitude $11^{\circ} 30^{\prime}-14^{\circ} 45^{\prime} \mathrm{E}$.

Collection and identification of plant materials: Fresh leaves and shoots of Salvadora persica L. and the root bark of Terminalia avicennoides were collected from neighboring townships, Monguno and Konduga, respective in Borno state of Nigeria in August 2008. The identities of the plants were authenticated by a plant taxonomist in the Department of Biological Sciences,
University of Maiduguri, Borno state. Voucher specimens (No. 545B) were deposited in the laboratory of the Department of Chemistry of the same institution where the preliminary phytochemical analyses were done. Each of the collected plant materials were separately air-dried, pulverized and kept in cellophane bags before extraction.

Preparation of plant extracts: About $200 \mathrm{~g}$ each of the powdered samples of the shoots and leaves of $S$. persica L. and root bark of $T$. avicennoides were separately subjected to exhaustive soxhlet extraction in $500 \mathrm{~mL}$ of distilled water for $6 \mathrm{~h}$. The extracts were then concentrated in vacuo in a rotary evaporator. There were then labeled and stored at $4^{\circ} \mathrm{C}$ until use (Trease and Evans, 2002).

Phytochemical screening: The different aqueous extract fractions of the shoots and leaves of S. persica L. and root back of $T$. avicennoides were separately subjected to preliminary phytochemical screening using standard procedures (Harborne, 1993; Trease and Evans, 2002).

Collection and identification of nematode eggs: Fecal samples were collected directly from the rectum of 30 sheep and goats of different breeds randomly selected during slaughter at the Maiduguri Metropolitan Abattoir. The samples were placed in polythene bags and transported to the laboratory for analysis. Egg counts were determined by the McMaster technique using saturated sodium chloride solution as the floating medium (Gordon and Whitlock, 1939; Nwosu et al., 2001). Only fecal samples with at least 500 Eggs Per Gramme (EPG) were used in the study.

Fecal culture and laval recovery: These were done using the test tube filter paper technique as described by Harada and Mori (1955). Identification of infective nematode larvae was done based on standard descriptions (Hansen and Perry, 1990, 1994; Anonymous, 1977).

Anthelmintic assay: The anthelmintic efficacy of the extracts at 25,50 and $100 \mathrm{mg} \mathrm{mL}^{-1}$ concentrations were determined by egg hatch assay as described by Kelly et al. (1981). Two commercially available anthelmintics, albendazole and levamisole (as positive control) were compared with the extracts for their efficacy in preventing egg hatch. Tap water was used as negative control. The number of eggs hatched was determined for the extract-treated and control culture samples and were then compared to the unhatched eggs to determine the percentage reduction in egg hatch. The proportion of 
unhatched eggs at each concentration of the extracts and drugs used were calculated by relating the number of hatched larvae to the total number of eggs cultured (Chiejina, 1984).

Statistical analysis: Data were analysed using computer statistical software package, Graphpad instat version 3.10, 32 bit for Windows, 2009 by GraphPad software inc. The reduction in egg hatch in fecal cultures treated with the plant extracts and those of the control groups were expressed as mean and standard deviation. Analysis of Variance (ANOVA) was used to compute the differences among means and $\mathrm{p}<0.05$ was considered significant.

\section{RESULTS AND DISCUSSION}

Phytochemical analysis: The result of the phytochemical screening of Salvodora persica L. shoots and leaves extracts and Terminalia avicennoides root bark extract are shown in Table 1. The result revealed slight to moderate presence of sterols and terpens, flavonoids, saponins, tannins and reducing sugars in all the extracts. Antracenocides are slightly present in S. persica L. shoots extract but absent in its leaves and the root bark of T. avicennoides. Slight to moderate presence of flavone aglycone were detected in $S$. persica $\mathrm{L}$. leaves and the root bark of $T$. avicennoides but absent in the shoots of $S$. persica L. Basic alkaloids were also moderately present in $T$. avicennoides stem bark and $S$. persica L. shoots but absent in the latter's leaves.

Anthelmintic assay: The result of in vitro anthelmintic efficacy of the aqueous extracts of $S$. persica L. and T. avicennoides compared to those of the control groups are shown in Table 2 and 3 , respectively. The percentage reductions in egg hatch were found to be concentration dependent as the highest dilution of the extracts produced the least inhibition in egg hatch and vice versa and these effects were significantly $(p<0.001)$ similar to the result of positive controls albendazole and levamisole although at the extracts' concentrations of 50 and $25 \mathrm{mg} \mathrm{mL}^{-1}$, the reductions in egg hatch were slightly less than those of the standard drugs.

The result of the phytochemical screening of aqueous extracts of shoots and leaves of Salvodora persica $\mathrm{L}$. and the root bark of Terminalia avicennoides revealed the presence of phytochemicals that are known to possess various pharmacologic activities and of therapeutic benefits. The result also showed that the extracts exhibit in vitro anthelmintic properties against strongyline nematodes. Studies on other plants have revealed that phytochemicals similar to those present in the extracts used in this study has anthelmintic activity.
Table 1: Phytochemical constituents of Salvadora persica and Terminalia avicennoides

\begin{tabular}{llll}
\hline & \multicolumn{3}{l}{ Salvadora persica $/$ Terminalia avicennoides } \\
& ---------- \\
Phytochemicals & $\mathrm{SP}_{\mathrm{L}}$ & $\mathrm{SP}_{\mathrm{S}}$ & $\mathrm{TA}_{\mathrm{RB}}$ \\
\hline Sterols/terpenes & ++ & + & + \\
Reducing components & + & + & + \\
Flavone aglycone & ++ & - & + \\
Anthracenosides & - & + & - \\
Flavonoids & ++ & + & + \\
Saponins & + & ++ & ++ \\
Tannins & + & + & + \\
Basic alkaloids & - & + & + \\
\hline
\end{tabular}

$++=$ Moderate presence, $\mathrm{SP}_{\mathrm{L}}=$ Salvadora persica leaf, $+=$ Slight presence, $\mathrm{SP}_{\mathrm{S}}=$ Salvadora persica shoot, $-=$ Absence and $\mathrm{TA}_{\mathrm{RB}}=$ Terminalia avicennoides root back

Table 2: In vitro efficacy of the aqueous extract of Salvadora persica (shoots and leaves) against strongyline nematodes

\begin{tabular}{lccc}
\hline Extract/drug & $\begin{array}{c}\text { Concentration } \\
\left(\mathrm{mg} \mathrm{mL}^{-1}\right)\end{array}$ & $\begin{array}{c}\text { No. of larvae } \\
\text { hatched } \\
\left(\mathrm{Mean} \pm \mathrm{SD}^{*}\right)\end{array}$ & $\begin{array}{c}\text { Percentage } \\
\text { reduction in } \\
\text { egg recovery (\%) }\end{array}$ \\
\hline Water control & - & $185.28 \pm 44.11$ & $0.0^{* * *}$ \\
$\mathrm{SP}_{\mathrm{A}}$ & 100.00 & $1.28 \pm 1.980$ & 98.9 \\
& 50.00 & $2.57 \pm 1.740$ & 98.9 \\
$\mathrm{SP}_{\mathrm{B}}$ & 25.00 & $18.64 \pm 5.410$ & 86.7 \\
& 100.00 & $1.42 \pm 1.700$ & 99.9 \\
Albendazole & 50.00 & $2.79 \pm 1.360$ & 98.3 \\
& 25.00 & $18.27 \pm 4.720$ & 72.4 \\
& 25.00 & 0 & 100.0 \\
Levamisole & 12.50 & $1.79 \pm 0.800$ & 99.5 \\
& 6.25 & $7.00 \pm 3.890$ & 98.3 \\
& 60.00 & 0 & 100.0 \\
& 30.00 & $2.0 \pm 4.7700$ & 98.9 \\
& 15.00 & $8.9 \pm 4.7300$ & 93.4 \\
\hline
\end{tabular}

*Mean standard deviation based on 10 observations, **Larval recovery for control (distilled water) culture used as standard reduction in egg hatch, $\mathrm{SP}_{\mathrm{A}}=$ Salvadora persica shoot extract, $\mathrm{SP}_{\mathrm{B}}=$ Salvadora persica leaf extract reductions (Mean $\pm \mathrm{SD}$ ) in the no. of larvae hatched in the extract treated groups are significant $(p<0.001)$ when compared to those of levamisole and albendazole (positive control)

Table 3: In vitro efficacy of the aqueous extract of Terminalia avicennoides (root bark) against strongyline nematodes

\begin{tabular}{lccc}
\hline & $\begin{array}{c}\text { Concentration } \\
\left(\mathrm{mg} \mathrm{mL}^{-1}\right)\end{array}$ & $\begin{array}{c}\text { No. of larvae } \\
\text { hatched } \\
\left(\mathrm{Mean} \pm \mathrm{SD}^{*}\right)\end{array}$ & $\begin{array}{c}\text { Percentage } \\
\text { reduction in egg } \\
\text { recovery (\%) }\end{array}$ \\
\hline Water control & & $114.7 \pm 16.25$ & $0.000^{* * *}$ \\
$\mathrm{TA}_{\mathrm{RB}}$ & 100.00 & $0.00 \pm 0.00$ & 100.000 \\
& 50.00 & $18.50 \pm 2.31$ & 83.700 \\
& 25.00 & $32.55 \pm 3.37$ & 71.580 \\
Albendazole & 25.00 & $0.00 \pm 0.00$ & 100.000 \\
& 12.50 & $13.35 \pm 2.52$ & 88.320 \\
& 6.25 & $28.60 \pm 2.58$ & 75.070 \\
Levamisole & 60.00 & $0.00 \pm 0.00$ & 100.000 \\
& 30.00 & $12.50 \pm 2.33$ & 89.100 \\
& 15.00 & $26.00 \pm 2.73$ & 77.310 \\
\hline
\end{tabular}

*Mean standard deviation based on 10 observations, **Larval recovery for control (distilled water) culture used as standard (\% reduction in egg hatch). $\mathrm{TA}_{\mathrm{RB}}=$ Terminalia avicennoides root bark extract. Reductions (Mean $\pm \mathrm{SD}$ ) in the no. of larvae hatched in the extract treated groups are significant $(p<0.001)$ when compared to those of levamisole and albendazole (positive control)

Tannins are polyphenolic compounds (Min et al., 2004; Ramirez-Restrepo et al., 2004; Makkar et al., 2007; Max et al., 2007) that have been reported to have profound anthelmintic effects (Butter et al., 2000; 
Athanasiadou et al., 2000, 2001; Max et al., 2005a, b, 2007). Reports on the mechanism by which tannins produce anthelmintic effect remain equivocal. Action similar to those of synthetic phenolic anthelmintics such as oxyclozanide, niclosamide and nitroxynil which interfere with energy generation in helminth parasites by uncoupling oxidative phosphorylation, consequently leading to depletion of parasite ATP has been reported (Martin, 1997). Other reports suggested tannins' ability to bind to free proteins in the gastrointestinal tract of host animal (Niezen et al., 1993; Wang et al., 1996; Athanasiadou et al., 2001) or to glycoproteins on the cuticle of parasites (Thompson and Geary, 1995), leading to death of the parasites. A form of terpene known as palasonin (a terpene anhydride) was reported to produce anthelmintic activity by inhibiting glucose uptake and depleting the glycogen content of parasites (Kumar et al., 1995). Similarly, gentistein (a form of flavone aglycone) was reported to produce anthelmintic effect which was linked to the possibly of its activity on nitric oxide synthatase (Kar et al., 2002). The anthelmintic effects of flavonoids were also reported (Lahlou, 2002; Trease and Evans, 2002).

Villasenor et al. (1998) and Cho et al. (2003) observed that better therapeutic effect may be obtained from a combination of active principles in each plant than by single isolated substance. Therefore, the individual or collective presence of the phytochemicals discussed above in the extracts used in this study may possibly constitute the basis for the profound anthelmintic activity exhibited by the extracts.

This study also revealed that the anthelmintic effects of all the extracts studied were concentration dependent which indicates that the extract exhibit graded anthelmintic efficacy. Reductions $(\mathrm{Mean} \pm \mathrm{SD})$ in hatched larvae in all the extract treated groups are significant ( $<<0.001$ ) when compared to those of the positive control group (albendazole and levamisole). This result holds a potential promise in the future use of materials from these plants as anthelmintics.

\section{CONCLUSION}

It is therefore concluded from this study that the shoots and leaves extracts of $S$. persica and root bark extract of $T$. avicennoides contain phytochemicals of therapeutic significance and have anthelmintic properties with proven efficacy against strongyline gastrointestinal nematodes. This finding has validated the basis for the traditional use of these plants against gastrointestinal helminthes in northeastern Nigeria. Researcher therefore recommend further bioassay guided fractionation and phytochemical analysis of the constituents of these extracts with the aim of possibly isolating the anthelmintic constituents.

\section{REFERENCES}

Adedapo, A.A., O.O. Shabi and O.A. Adedokun, 2005. Antihelmintic efficacy of the aqueous crude extract of Euphorbia hirta Linn in Nigerian dogs. Veterinarski Arhiv, 75: 39-47.

Anonymous, 1977. Manual of veterinary parasitological laboratory techniques. Technical Bulletin No. 18. Ministry of Agriculture, Fisheries and Food, London, pp: 129.

Athanasiadou, S., I. Kyriazakis, F. Jackson and R.L. Coop, 2000. Consequence of long-term feeding with condensed tannins on sheep parasitized with Trichostrongylus colubriformis. Int. J. Parasit., 30: 1025-1033.

Athanasiadou, S., I. Kyriazakis, F. Jackson and R.L. Coop, 2001. Direct anthelmintic effects of condensed tannins towards different gastrointestinal nematodes of sheep: In vitro and in vivo studies. Vet. Parasitol., 99: 205-219.

Butter, N.L., J.M. Dawson, D. Wakelin and P.J. Buttery, 2000. Effect of dietary tannin and protein concentration on nematode infection (T. colubriformis) in lambs. J. Agric. Sci., 134: 89-99.

Chiejina, S.N., 1984. Bovine parasitic gastro-enteritis in Nsukka: Worm egg output and herbage infestation following dry season calving and the performance of calves during their first grazing season. Trop. Vet., 2: 125-132.

Cho, E.J., T. Yokozawa, D.Y. Rhyu, S.C. Kim, N. Shibahara and J.C. Park, 2003. Study on the inhibitory effects of some Korean medicinal plants and their main compounds on the 1, 1-diphenyl-2-picrylhydrazyl radical. Phytomedicine, 10: 544-551.

Coles, G.C. and R.T. Roush, 1992. Slowing the spread of anthelmintic resistant nematodes of sheep and goats in the United Kingdom. Vet. Res., 130: 505-510.

Dawo, F. and M. Tibbo, 2005. Anthelmintic effect of Halothamus somalensis in Arsi-Bale goats. Livestock Res. Rural Dev., Vol. 17.

Fakae, B.B., 1990. The epidemiology of helminthosis in small ruminants under the traditional husbandry system in Eastern Nigeria. Vet. Res. Commun., 14: $381-391$.

Githiori, J.B., J. Hoglund, P.J. Waller and R. Baker, 2003a. The anthelmintic efficacy of the plant Albizia anthelmintica against the nematode parasites Haemoncus contortus of sheep and Heligmosomoides polygyrus of mice. Vet. Parasitol., 116: 23-34. 
Githiori, J.B., J. Hoglund, P.J. Waller and R. Baker, 2003b. Evaluation of anthelmintic properties of extracts from some plants used as livestock dewormers by pastoralist and smallholder farmers in Kenya against Heligmosomoides polygyrus infection in mice. Vet. Parasitol., 118: 215-226.

Gordon, H.M. and H.V. Whitlock, 1939. A new technique for counting eggs in sheep feaces. J. Council Sci. Ind. Res., 12: 50-52.

Hammond, J.A., D. Fielding and S.C. Bishop, 1997. Prospects for plant anthelmintics in tropical veterinary medicine. Vet. Res. Comm., 21: 213-228.

Hansen, J. and B. Perry, 1990. The Epidemiology, Diagnosis and Control of Gastro-Intestinal Parasites of Ruminants in Africa. International Livestock Research for Animal Disease (ILRAD), Nairobi, Kenya, pp: 121.

Hansen, J. and B. Perry, 1994. The Epidemiology, Diagnosis and Control of Helminth Parasites of Ruminants. 2nd Edn., Nairobi, Kenya, Ilrad, ISBN: 929055-703-1, pp: 171.

Harada, Y. and O. Mori, 1955. A new method for culturing hookworm. Yonago Acta Med., 1: 177-179.

Harborne, J.B., 1993. Phytochemical Methods: A Guide to Modern Technique of Plant Analysis. Chapman and Hall, London, pp: 56-68.

Jan, U., K. Lanislav, L. Iva and M. Jana, 2008. In vitro anthelmintic effect of medicinal plant used in Czech Republic. Pharmaceut. Biol., 46: 808-813.

Kar, P.K., V. Tandon and N. Saha, 2002. Anhelminthic efficacy of Flemingia vestita: Genistein-induced effect on the activity of nitric oxide synthtase and nitric oxide in the trematode parasite, Fasciolopsis buski. Parasitol. Int., 51: 249-257.

Kelly, J.D., J.L. Webster and D.L. Griffin, 1981. Resistance to benzimidazole anthelmintics in equine strongyles. 2. Evidence of side-resistance and susceptibility of benzimidazole-resistant strongyles to non-benzimidazole compounds. Australia Vet. J., 57: 172-181.

Kumar, D., S.K. Mishra, S.K. Tandan and H.C. Tripathi, 1995. Possible mechanism of anthelmintic action of palasonin on Ascaridia galli. Indian J Pharmacol., 27: $161-166$.

Kusiluka, L. and D. Kambarage, 1996. Common Diseases of Sheep and Goats in Sub-Saharan Africa: Diseases of Small Ruminants A Handbook. 1st Edn., Center for Tropical Veterinary Medicine, Scotland.

Lahlou, M., 2002. Potential of Origanum compactum as a cercaricide in Morocco. Ann. Trop. Med. Parasitol., 96: 587-593.
Makkar, H.P.S., G. Francis and K. Becker, 2007. Bioactivity of phytochemicals in some lesser-known plants and their effects and potential applications in livestock and aquaculture production systems. Animal, 1: $1371-1391$

Martin, R.J., 1997. Mode of action of Anthelmintic drugs. Vet. J., 154: 11-34.

Mascie-Taylor, C.G.N. and E. Karim, 2003. The burden of chronic disease. Science, 302: 1921-1922.

Max, R.A., A.E. Kimambo, A.A. Kassuku, L.A. Mtenga and P.J. Buttery, 2007. Effects of tanniferous browse meals on nematode faecal egg counts and internal parasites burdens in sheep and goats. S Afr. J. Anim. Sci., 37: 97-106.

Max, R.A., D. Wakelin, J. Craigon, A.A. Kassuku, A.E. Kimambo and L.A. Mtenga, 2005a. Effect of two commercial preparations of condensed tannins on the survival of gastro-intestinal nematodes of mice and goats in vitro. S. Afr. J. Anim. Sci., 35: 213-220.

Max, R.A., D. Wakelin, J. Dawson, A.E. Kimambo, A.A. Kassuku, L.A. Mtenga and P.J. Buttery, 2005b. Effect of quebracho tannin on faecal egg counts, worm burden and performance of temperate sheep with experimental nematode infections. J. Agric. Sci., 143: 519-527.

McLeod, R.S., 1995. Cost of major parasites to the Australian livestock industries. Int. J. Parasitol., 25: 1363-1367.

Min, B.R., W.E. Pomroy, S.P. Hart and T. Sahlu, 2004. The effect of short-term consumption of a forage containing condensed tannins on gastro-intestinal nematode parasite infections in grazing wether goats. Small Ruminant Res., 51: 279-283.

Monteiro, A.M., S.W. Wanyangu, D.P. Kariuki, R. Bain, F. Jackson and Q.A. McKellar, 1998. Pharmaceutical quality of anthelmintics sold in Kenya. Vet. Records, 142: 396-398.

Mulugeta, M., F. Gebre-Ab and G. Abebe, 1987. Effects of sub-clinical parasitism on milk yield of crossbred (Friesian x Arsi) dairy cattle in co-operative Dairy Farms of Chilalo Awraja. Proceedings of the First National livestock Improvement Conference, Feb. 11-13, Institute of Agricultural Research, Addis Ababa, Ethiopia, pp: 125-128.

Mwamachi, D.M., J.O. Audho, W. Thorpe and R.L. Baker, 1995. Evidence for multiple anthelmintic resistance in sheep and goats reared under the same management in coastal Kenya. Vet. Parasitol., 60: 303-313.

Nawathe, D.R., A.S. Sohael and I. Umo, 1985. Health management of dairy herd on Jos Plateau (Nigeria). Bull. Anim. Health nd Prod. Afr., 33: 199-205. 
Niezen, J.H., T.S. Waghorn, G.C. Waghorn and W.A.G. Charleston, 1993. Internal parasites and lamb production-a role for plants containing condensed tannins. Proc. New Zealand Soc. Anim. Prod., 53: 235-238.

Nwosu, C.O., N.K. Haruna, V.O. Ogugbuaja, J.A. Akiniyi and P.A. Onyeyili, 2001. Anthelmintic efficacy of ethanolic stembark extract of Sacoglottis gabonensis (Bail) against strongyline nematodes of small ruminants. J. Life Environ. Sci., 2: 127-130.

Payne, W.J.A., 1990. An Introduction to Animal Husbandry in Tropics. 4th Edn., Longman Scientific and Technical/John Willey and Sons, UK., pp: $472-536$.

Prichard, R., 1994. Anthelmintic resistance. Vet. Parasitol., 54: $259-268$.

Ramirez-Restrepo, C.A., T.N. Barry, N. Lopez-Villalobos, P.D. Kemp and W.C. McNabb, 2004. Use of $L$. corniculatus containing $\mathrm{CT}$ to increase lamb and wool production under commercial dryland farming conditions without the use of anthelmintics. Anim. Feed Sci. Technol., 117: 85-105.
Suleiman, M.M., M. Mamman, A. Aliu and I. Ajanus, 2005. Anthelmintic activity of crude methanol extract of Xylopia aethiopica against Nippostrongylus brasilliensis in rats. Veterinarski Arhiv, 75: 487-495.

Thompson, D.P. and T.G. Geary, 1995. The Structure and Function of Helminth Surfaces. In: Biochemistry and Molecular Biology of Parasites, Marr, J.J.( Ed.). 1st Edn., Academic Press, NewYork, pp: 203-232.

Trease, G.E. and W.C. Evans, 2002. Pharmacological Activities: Pharmacognosy. 15th Edn., Saunders Publishers, London, pp: 42-44.

Villasenor, I.M., M.A. Cabrera, K.B. Meneses, V.R.R. Rivera and R.M. Villasenor, 1998. Comparative antidiabetic activities of some medicinal plants. J. Ethnopharmacol., 22: 1-2.

Waller, P.J., 1997. Anhelmintic resistance. Vet. Parasitol., 72: 391-405.

Wang, Y., G.C. Douglas, T.N. Barry and A.G. Foote, 1996. Effect of CTs in Lotus corniculatus upon the digestion of methionine and cysteine in the small intestine of sheep. J. Agric. Sci., 127: 413-421. 